\title{
Impact of Covid-19 on SMEs Globally
}

\author{
Singh Kamaldeep ${ }^{1, *}$ \\ ${ }^{1}$ University of Turiba, Faculty of Business Administration, Riga ,Latvia ( LV-1058)
}

\begin{abstract}
Research background: The ongoing Covid-19 pandemic has created irreversible damage to the world economy. Businesses ranging from local shops to multinational companies are suffering extensively due to the lockdowns in place. Amon this the unorganized sector is the worst hit as majority of the stakeholders have no alternative income. This makes a study in SMEs much more necessary as this sector is extremely volatile and even the slightest fluctuations in the economy causes huge losses for them.

Purpose of the article: This study is aimed at analyzing the degree of impact of the ongoing Covid-19 pandemic on SMEs globally.

Methods: This research, by design, is descriptive and exploratory and its objective is to determine, based on the appreciation that managers or those responsible for the financial management of SMEs have, how it impacts to their finances the health crisis caused by COVID-19 for the development and investment of their business.

Findings \& Value added: The results obtained in the research show that the health crisis caused by the COVID-19 has been a challenge for SMEs because it has generated a strong crisis, but they have shown cautious in the measures to face it, and financial management strategies aimed at avoiding indebtedness. In conclusion, the management of SMEs is aware that to face the new modality it is necessary to carry out administrative and financial management based on foreseeable strategies, considering the changes aimed at the development and investment of their businesses.
\end{abstract}

Keywords: Financial Management; COVID-19; Health Crisis; Challenge; SMEs

JEL Classification: $A 11 ; A 14 ; B 16$

\footnotetext{
* Corresponding author: kampreet0001@,gmail.com
} 


\section{Introduction}

The socioeconomic and productive impact of COVID-19 will surely be the subject of study for years, the world is still in the middle of the first outbreak and a new outbreak. In the present tomes, complex and recessive scenario that had been going through, the pandemic of COVID-19, whose final impact on the internal productive tissue is unknown due to the nature unprecedented situation.

The United Nations set out from the beginning to monitor permanently the situation of the business segment that generates a bulk of global employment (Belacín and Arnoletto, 2019), carrying out surveys among companies with up to 1000 employed persons, under the Coronavirus Research Program: Impact on SMEs, production and employment. They received more than 6,000 responses, through surveys at the firm level among the Primary sectors (Agriculture / Livestock / Forestry / Fishing / Mining), Services, Commerce, Manufacturing Industry and Construction, throughout the entire national territory. So far, five surveys have been carried out investigating the impact of the pandemic, public interventions implemented and the business actions taken regarding productive operation, employment, financial situation and internal organization.

Days prior to the imposition of Social, Preventive and Mandatory Isolation, the first survey, where these companies were already active in measures to mitigate the risk of contagion, in case of continuing to operate. Between the period from early April to early April June, the UN conducted four more surveys to identify different aspects of the productive activity, employment, management and strategies of the segment. At the time of preparing this work A sixth survey is in the field that inquiries about operability, staff activity, evolution of billing and remote work.

It is aggravated by COVID-19. Regarding the rhythm of activity and employment, it can be seen that the degree of operability of the firm does not it directly implies the same degree of activity from your staff. The proportion of inactive staff of companies responds to: i) processes and internal organization, ii) regulatory restrictions to be able to function, and iii) fall in the supply and demand of goods and services that the pandemic implied In relation to the tools used by companies to mitigate the impact of the pandemic, the intense dynamics followed to adapt and cope with the new circumstances can be highlighted, although the surveys carried out by UN reveal that the group of firms of up to 50 employed people suffer especially from the difficulties of the context and also the firms in the Construction. In this regard, public assistance with transfers is specially analysed directives and suspension agreements between companies and employees or unions.

The public assistance program for salaries and employer contributions (Program for Emergency Assistance to Production and Work) was important and well received by the companies, although it has not managed to avoid a high financial fragility in a part of the firms of smaller dimension and thus about $10 \%$ of them declared to be evaluating to close definitively. However, just over $40 \%$ of these firms do not have any possibility of ending 2020 with its staff working remotely, an aspect that is prints as a new factor of productive dualization.

Throughout the study presented here, it will be detected that the Central region is the territory with the highest proportion of sustainable companies (high degree of operability, high rate of staff activity, good access to public assistance tools, low risk of closure, low risk of conflict employment, high possibility of telework implementation), the sector of primary activities is that of the best prospects and companies with more than 50 employees are the relatively least threatened. That is, a deepening of the pre-existing productive asymmetries in the country at the regional level, sector and by size.

The document is structured as follows. In the next section, a succinct mention will be made of some works that study the socioeconomic and / or productive impact of COVID-19. Then I know briefly describe in the second section some methodological aspects that are at 
the base of the analysis that will be covered in sections 4 on activity, employment, business actions, public interventions and remote work. Finally, some comments and reflections are outlined end.

\section{Literature Review}

There is a very abundant number of works in the international and local literature that have been published in recent months on economic, social and productive topics related to the pandemic, its effects, public interventions adopted and private strategies to face it. An attempt will be made to guide the readers in some selected works (Cowling et al., 2020; CaballeroMorales, 2021; Al-Fadly, 2020; Belghtar et al., 2021...).

Baldwin and Di Mauro (2020) collect the contributions of different experts on the macroeconomics of the pandemic, in a prospective analysis based on the first effects that could be observed at a global level and punctually in some countries where a first phase of the pandemic. Information is used both on the evolution of economic activity, such as international trade, monetary policy, financial regulation, among other topics. They take considering also the statistics and reflections of international organizations on the global outlook under the impact of the deep shock that is the COVID-19 pandemic. Could It can be said that this book is a tour of some general aspects, which can serve as a context to know the perspectives developed in the beginning. Then both the Organization for Cooperation and Economic Development such as the International Monetary Fund and the World Bank, to name some organizations, they were re-editing their prospective analyses based on statistics calibrated with the advances throughout the world of the new virus.

Among the international studies based on surveys, it is worth mentioning two carried out at the level of company in the United States. The first of them (Bartik et al, 2020) is an analysis of Descriptive Statistics on Survey Responses to American Small Business Owners during late March and early April. It focuses on measuring financial fragility, the degree of operability of the firms and downtime of its staff, expectations about the duration of the crisis, and access to public assistance programs and their impact on inactivity and closing decisions. Utilizes over 5,800 responses obtained on a small business basis dimension of the United States, for a survey consisting of 43 questions (some on hypothetical scenarios, rather behavioral or experimental questions). The distribution of the response base at the regional level and by size is similar to that of the 2017 Economic Census. The main findings consist of the high financial fragility shown by many of the minor companies; an inoperability close to $45 \%$ of the firms, with a reduction in employment close to $40 \%$ in relation to the beginning of 2020; and a significant interest from companies in public assistance programs, which hoped to adjust their decisions based on aid received, although a part of the segment was reluctant to apply due to questions of administrative complexity and eligibility; Finally, the expected duration of the crisis is extended until mid-summer (July-August 2020), although with a high dispersion between the answers.

The second work (Bartik et al., 2020) is also an analysis of the results of two surveys that inquire about the modality of remote work during the pandemic. One of them conducted among nearly 1,800 small business leaders (a sample drawn from the survey used in the research referred to in the previous paragraph) and another among 70 business economists from the National Association of Business Economists (NABE). Were made between March and April, respectively, a period during which much of the North American country was under isolation restrictions (stay-at-home restrictions). They also use a measure that allows the feasibility of remote work implementation at the industry level. Among SMEs, find that $45 \%$ had workers transitioning to remote work (at least two days a week), while among the largest companies (results of the survey among economists NABE) that proportion is higher. Through some regression analysis, they also find that the signature size does not generate 
significant differences in the teleworking implementation, but that it is more widespread (or more feasible) in industries with more qualified and better personnel payment. Respondents reveal lost productivity when moving to telecommuting, but this Loss is also lower in industries with higher human resources qualification and higher remuneration. A general conclusion is that the implementation of remote work reinforces the inequities.

On the other hand, for the Latin American region, it is especially useful to point out the IDB document (2020), where responses to COVID-19 are discussed from science, innovation and development productive (focusing on business measures and public interventions). There they stand out, on the other hand, the needs and opportunities of public policy in the region, as well as the centrality of the capacities already installed in the different economies. Some statistics presented correspond to different surveys at the company level, although in few countries given that it was spread at a rather incipient stage of the pandemic in Latin America. The route of some examples of public interventions adopted in financial, labor and technological matters, including developing as well as developed countries in the region, as well as the reference to programs applied in various countries outside the region, developed economies but very different from each other, such as Korea from the South, Germany, the United States or Denmark. This IDB work also does some policy recommendations for the post-pandemic, in terms of the prospects for great fragility and deterioration that may characterize the region once the pandemic has passed. Some of them, in order to encourage innovation and entrepreneurship to accelerate the recovery economic, are the increase in the scale of financing for innovative start-ups, the financing of sectoral knowledge assets, greater technical support for transformation digital node of entrepreneurship and innovation, among others.

The productive structure of the region has accumulated weaknesses for decades, with strong heterogeneities between sectors and companies. There are also external productivity gaps and internal and the pandemic arrives on these structural conditions. A special report from ECLAC (2020) analyses the productive and business situation in the region, where the pandemic is showing a strong negative impact on sectors that generate a third of formal employment and a quarter of PBI, and in technology-intensive sectors in particular. The agency anticipates the closure of more than 2 million companies throughout the region, especially the smallest ones. In relation to policies implemented, qualifies them as important but insufficient. The work suggests expanding the lines of financing and reinforcing direct transfers to companies.

There is no doubt that to understand recent financial systems, and first you must analyse the most recent data available on the situation before the Covid-19 pandemic, According to figures from the International Monetary Fund (IMF). The outlook is bleak: the projection is that the Mexican economy will contract by $5.2 \%$, and it is important to consider that SMEs are companies that depend on daily sales and have little or no reserves of liquidity, they may also be under severe financial stress and may have to lay off workers, as described in a report published on April 9, 2020 by the Inter-American Development Bank (IDB).

The pandemic caused by COVID-19, has generated a problem in the field of economically and has significantly deteriorated the prospects that SMEs had of achieving a growth. The International Monetary Fund (IMF, 2020) and the Economic Commission for Latin America and the Caribbean (ECLAC, 2020) estimate that Mexico's growth during 2020 it will be around $-6.6 \%$; as a consequence of the quarantines implemented, due to the lower remittances, lower prices of raw materials, lower income from tourism, the greater aversion to risk on the part of international investors, the outflows of capital and higher volatility in financial markets.

Future expectations are a mystery, since the COVID-19 crisis has the consumers and businesses in continuous uncertainty, furthermore, it indicates that some indicators, such as the Purchasing Manager Index (PMI -), have fallen drastically and that from the PMI it can 
be determined whether an economy is in good health, and take action beforehand if data indicates a possible recession, that is why this indicator is especially important to be able to venture into a economic crisis and reduce its impact by promoting measures, since the PMI data is used by financial professionals to understand the direction and the expectations of each economy (Owen, 2020).

\section{Methodological Aspects}

This work consists of a descriptive analysis of the situation of the lower-income business segment dimension during the COVID-19 pandemic based on data collected from the multisectoral surveys. The responses were collected from a structured questionnaire available in an online and anonymous platform. The questionnaire for each operation was made available of a set of companies from the base of the SME Observatory Foundation stratified and representative of the universe of firms with up to 800 employed persons. 653 responses were obtained from these companies throughout the five surveys. The surveys were aimed at owners, managers and responsible for administration and accounting.

The main topics surveyed refer to the impact on the activity of companies, the production and employment; business strategies; occupational risk; the interventions implemented public and possible modifications of the forms of work.

\section{Results}

Image 1 shows that for $46 \%$ of SMEs in the retail trade sector were impacted by COVID-19 has been very negative, for $32 \%$ it has been something positive, for $10 \%$ it has been something positive, for $9 \%$ very positive and for 3\% it is neutral. The results show that the situation of SMEs in the commerce sector during the contingency generated by COVID-19 has been affected.

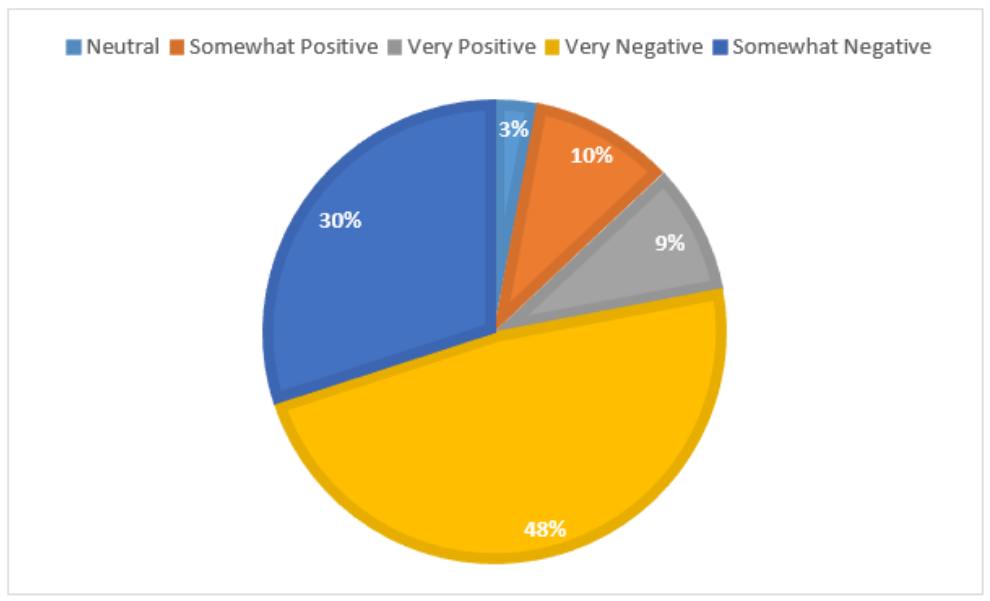

Image 1. Impact of the health crisis caused by COVID-19.

Image 2 shows that for $46 \%$ of SMEs in the retail trade sector were impacted by COVID19 has been very negative, for $32 \%$ it has been something positive, for $10 \%$ it has been something positive, for $9 \%$ very positive and for 3\% it is neutral. The results show that economic activity during the period of March 20 as of August 20, 2020 of SMEs in the commerce sector during the contingency generated by COVID-19 has been affected, the above allows suppose that in order to face it, financial management strategies were rethought. 


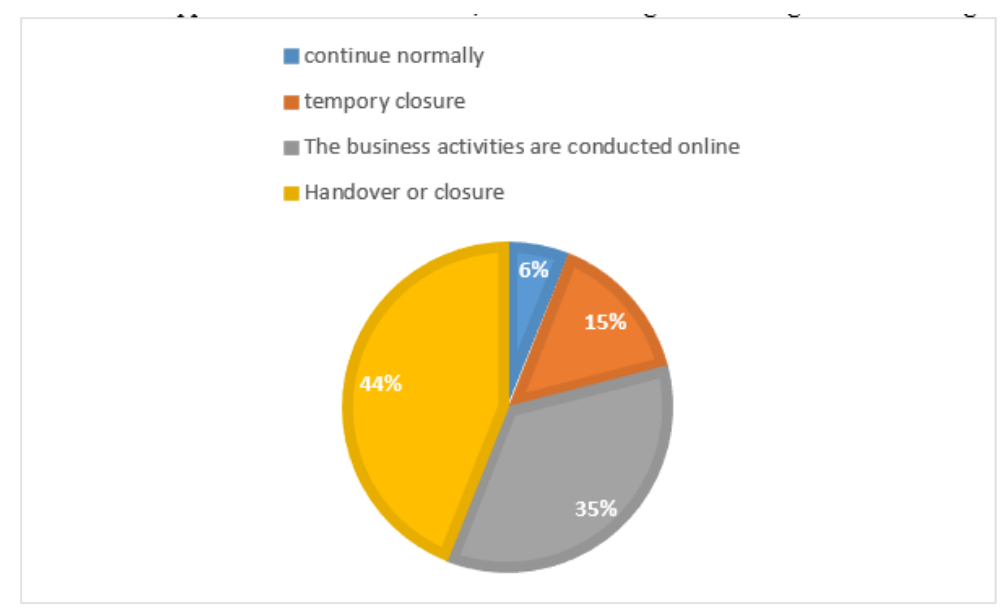

Image 2. Economic activity during the period from March 20 to August 20, 2020

Image 3 shows that for $48 \%$ of the SMEs in the commercial sector was impacted by COVID-19, its main problem generated was the reduction in demand, for $37 \%$ it has been the increase in their debts, for $35 \%$ it has been the closing of credits, for $22 \%$ the reduction of public aid and for $20 \%$ it is the reduction investment. The results show that the main problem for SMEs in the sector trade during the contingency generated by COVID-19 has been particularly affected due to the reduction in demand and the increases in its debts and the closings of the openings of financial support to be able to face them.

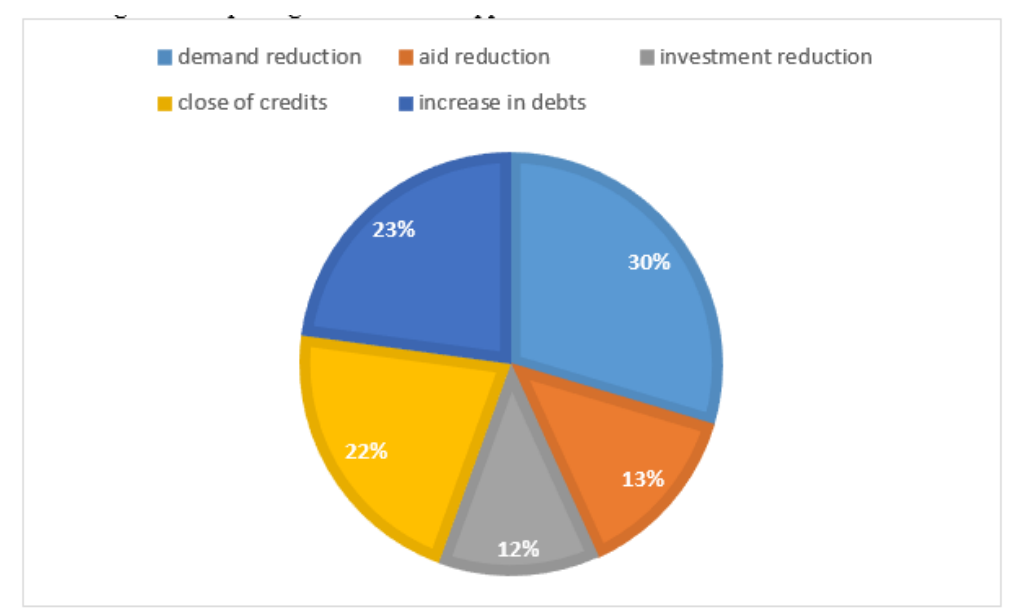

Image 3. Main problems

Image 4 shows that for $54 \%$ of the SMEs in the commercial sector adopted financing injection as financial management strategies, $23 \%$ their adopted financial management strategy is deferral and $13 \%$ is debt renegotiation. The results show that the entrepreneur seeks to keep his business, the foregoing allows us to assume that he sought new and varied forms of financing to keep your business. 


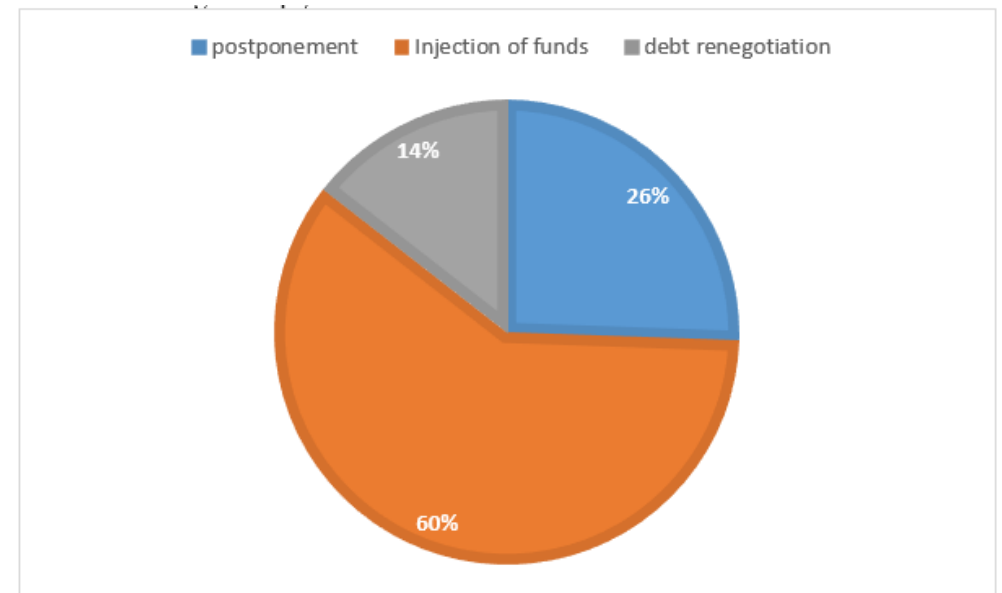

Image 4. Financial management strategies adopted from the COVID-19 pandemic

Image 5 shows that for $46 \%$ of the SMEs in the commercial sector used to face the challenge of the crisis has been family and friends, for $20 \%$ it was commercial credit, for $18 \%$ suppliers, risk capital and leasing for $5 \%$, others for $4 \%$ and alliances for $2 \%$. The results show that the main financial management measure to face the challenge of the crisis on the part of the SMEs was their own family and friends, the foregoing suggests that the businessman was cautious in debt measures.

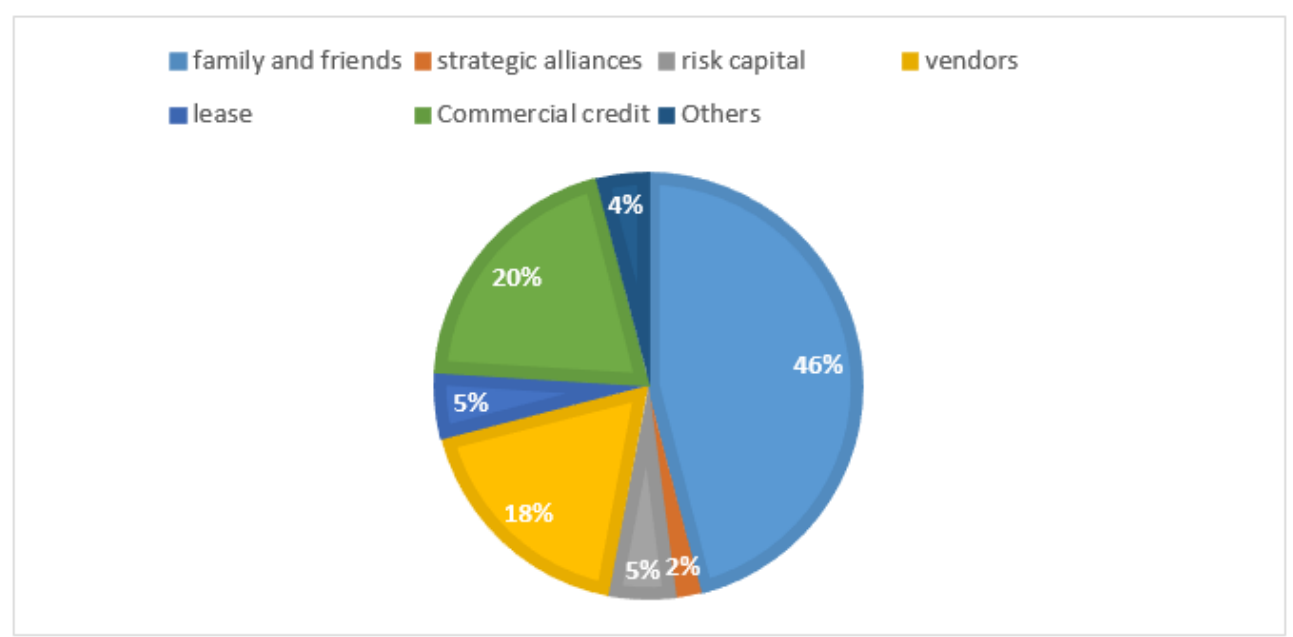

Image 5. Type of financing used to face the challenge of the COVID-19 crisis

Image 6 shows that for the SME manager, when making a profile of risk to face the crisis your most important priority is to know the level of indebtedness current and, least important are cash flow forecasts. Considering the importance of this profile is observed in second place of the profile are the limitations and current resources of the company, in third place the liquidity and solvency of the company, in fourth place is the risk of credits and fifthly, the need for the objective for which the debt is sought. The results show that the entrepreneur is showing caution in the case of indebtedness, which above suggests that the employer is aware that the profitability of his business in moment of crisis cannot sustain an investment at the moment because it is oriented to increase the value of the company and the outlook is still very uncertain. 


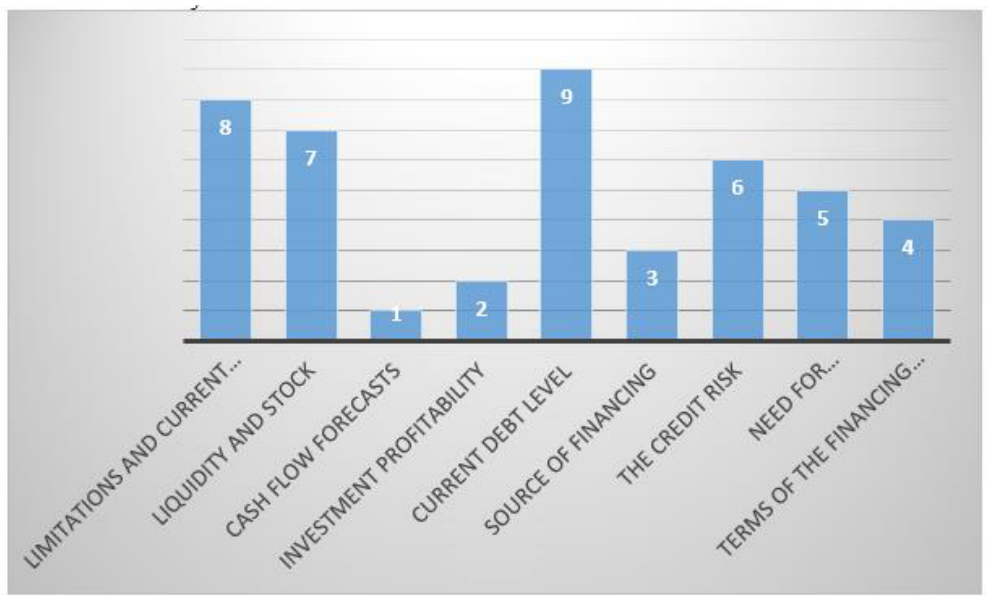

Image 6. Risk profile to face the crisis from the perspective of the SME manager, considering 1 the least and 9 the most relevant

Image 7 shows, for $30 \%$ of the analysed sample, the main expectations for short-term are innovation in financial management strategies, $29 \%$ new products and new markets, $14 \%$ their expectations are to request new credits and / or financing, the $11 \%$ seek support in public organizations, $10 \%$ reduction of personnel and $6 \%$ new investors. The results obtained show that the SME entrepreneur is aware of the need to create innovation in their financial management strategies and to generate new products and new markets, the above suggests that it will continue to seek the possibility such Instead of reinventing itself in its administrative management strategies, for which the financial information that can be provided by the finance department.

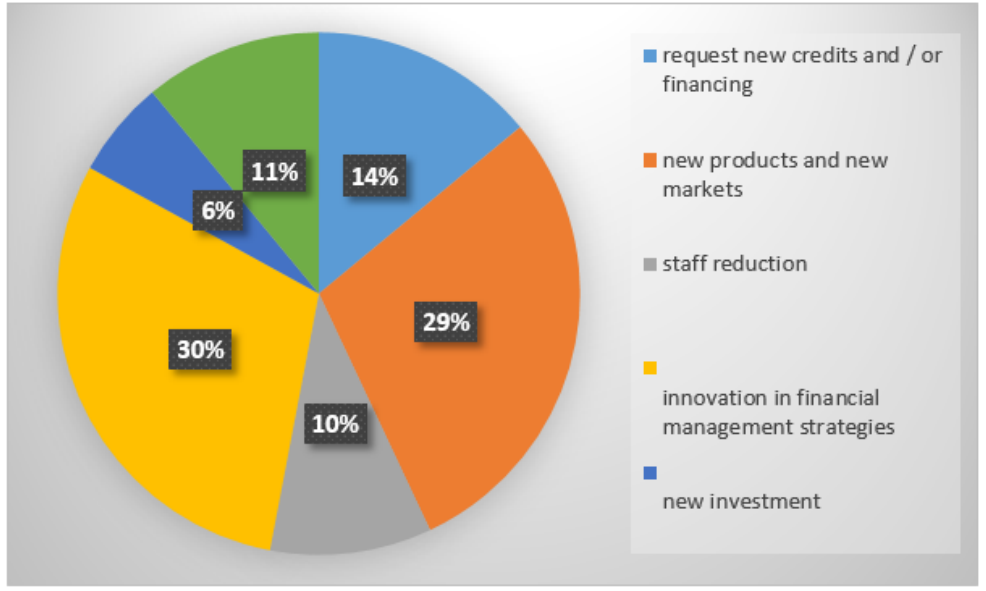

Image 7. Short-term expectations

Figure 8 shows that more than a third of the CFOs of the companies SMEs of the analysed sample estimate that it will take between 6 to 12 months to resume operations normal, despite the fact that $69 \%$ considered that the company would take up to six months recover from the effects of the pandemic. The results obtained show that the entrepreneur seeks to rescue its business in the short term, the above suggests the importance of generate effective financial management strategies to face the current crisis situation. 


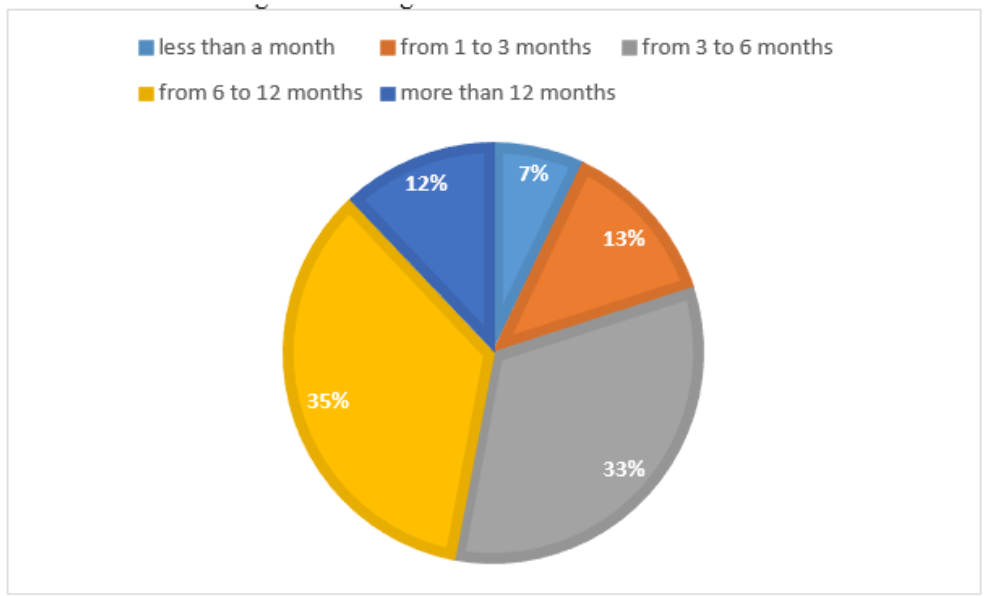

Image 8. If COVID-19 ended today, how long would it take for your company "back to normal"?

The results show that the situation of SMEs in the commerce sector during the contingency generated by COVID-19 has been affected by the reduction in demand, increases in their debts and the closing of financial support openings in order to face them. Many small entrepreneurs, in their eagerness to keep their business, looked for new and various forms of financing for investment, where their first option was their own family and friends, the above suggests that the businessman was cautious in debt measures because it is aware that the profitability of its business in times of crisis cannot sustain an investment at the moment because it is aimed at increasing the value of the company and the outlook is still very uncertain.

\section{Conclusions}

Although there are different ways in which shareholders can finance the growth of the companies, the adequate obtaining of economic resources is an issue that directly impacts their performance, so it is essential that every company structure its growth aligning its financial strategy with the maturity of its business with the objective of not incur unnecessary financial risks that could compromise your future. With a uncertain panorama on the evolution of the pandemic and its impacts, we do not know how many MSMEs will survive the onslaught of COVID-19, nor how policies will be promoted public policies and mechanisms to help these companies improve their financial situation, stay in the market and grow in the short and medium term.

Financial management for SMEs translates into the way these companies employ its resources efficiently to generate value through how to capitalize the business, where to acquire the resources and how to ensure that the shareholders obtain the desired benefits. The research results presented here validate the results obtained. previously in the exploratory stage and, when comparing it with the current situation of the impact of the pandemic caused by COVID-19, allows us to test the objective of the research and determine the importance of financial management in SMEs, as a control tool that helps manage and take advantage of your economic resources for your development and investment. The foregoing highlights the viability of the present project of research, defining with the results presented here, the importance of creating and implement within the financial management of their businesses, strategies that help them achieve the development and investment of their businesses and considering the current situation that exists, it is important to focus on three aspects: working capital, current liabilities and management efficient cash flow. 
As a final conclusion and considering the previous approaches, it is proposed work as a financial management strategy for SMEs that take into consideration that to increase the liquidity of the company it is necessary to carry out three key actions: reduce inventory, try to collect as soon as possible and delay payments as long as that does not mean paying commissions or waiving discounts soon payment. The realization of this project is considered viable since Sonora has a sector very dynamic economy that could help in the state economy, because the fragility SMEs' financial support in scenarios of generalized crisis requires the extraordinary support of the State, to guarantee the continuity of the productive activity as well as the maintenance of jobs. This study has several limitations that suggest they are works in future research avenues. The perception of the financial management strategies they use in successful medium-sized and larger companies, it is a result that must be analysed in order to rule out relativity to your size and business success. Later, it would be interesting delve into the effects of correlation between other variables that complement this work and help to improve the work carried out by SMEs that allow them to face the market current to which they belong.

\section{References}

1. Al-Fadly, A. (2020). Impact of Covid-19 on SMEs and employment. Entrepreneurship and sustainability issues, 8(2), 629-648.

2. Belghitar, Y., Moro, A., \& Radic, N. (2021). When the rainy day is the worst hurricane ever: the effects of governmental policies on SMEs during COVID-19. Small Business economics.

3. Bularafa, B. A., \& and Adamu, U. G. (2021). Effect of COVID-19 Pandemic on SME Performance in Nigeria. Advanced International Journal of Business, Entrepreneurship and SMEs, 3(7), 75-92.

4. Caballero-Morales, S. O. (2021). Innovation as recovery strategy for SMEs in emerging economies during the COVID-19 pandemic. Research in international business and finance, 57.

5. Cowling, M., Brown, R., \& Rocha, A. (2020). Did you save some cash for a rainy COVID-19 day? The crisis and SMEs. Journal-researching entrepreneurship, 38(7), 593-604.

6. ECLAC (2020, April 3). COVID-19 Special report. Latin America and the Caribbean and the COVID-19 pandemic. Economic and social effects. https://repositorio.cepal.org/bitstream/handle/11362/45351/6/S2000263_en.pdf

7. Gasparini, C., Molinari, A., \& Patrucchi, L. (2020). International credit organizations facing the COVID-19 crisis in Latin America: what? excuse me? and how much?. EcMagazine administration and economics, (4), 11-28.

8. Goldstein, E. (2011). Credit to SMEs in Argentina: Recent evolution and study of a innovative case. Santiago de Chile: United Nations.

9. González-Díaz, R. R., \& Perez, L. A. B. (2015). Business financial analysis of the sector trade as a factor of competitiveness through fuzzy logic. Strategy, 1(1), 1-10.

10. González-Díaz, R. R., Lara, R. J. V., López, R. O., \& Hernández-Royett, J. (2016). Tax on advertising and commercial advertising: An analysis from Municipal Tax Management. Globalciencia, 2(1), 20-34.

11. IMF (2020). Contraction of the World Economy: COVID-19. ProQuest. 
12. INEGI (2018). National Survey on Productivity and Competitiveness of Micro, Small and Medium Enterprises 2018. https://en.www.inegi.org.mx/programas/enaproce/2018/

13. SME Finance Forum (2019). Financial gap of the MYPYMES. https://www.smefinanceforum.org/data-sites/msme-finance-gap

14. Inter-American Development Bank (2020). Policies to Fight the Pandemic 2020 Latin American and Caribbean Macroeconomic Report. https://flagships.iadb.org/en/MacroReport2020/Policies-to-Fight-the-Pandemic

15. Islam, M. A., Igwe, P. A., Rahman, M. \& Saif, A. N. M. (2021). Remote working challenges and solutions: Insights from SMEs in Bangladesh during the COVID-19 pandemic. International Journal of Quality and Innovation, 5(2), 119-140.

16. Kumar, A., \& Ayedee, D. (2021). Technology adoption: A solution for SMEs to overcome problems during COVID-19. Academy of Marketing Studies Journal, 25(1), $1-16$.

17. Lu, L., Peng, J., Wu, J., \& Lu, Y. (2021). Perceived impact of the Covid-19 crisis on SMEs in different industry sectors: Evidence from Sichuan, China. International Journal of Disaster Risk Reduction, 55, Article 102085.

18. OECD / CAF (2019), Latin America and the Caribbean 2019: Policies for competitive SMEs in the Pacific Alliance and participating countries from South America. OECD Publishing, Paris.

19. Owen, L. (2020, May 8). Coronavirus: Five ways virus upheaval is hitting women in Asia. BBC News. https://www.bbc.com/news/world-asia-51705199

20. Urquía, E., Pérez, R., \& Muñoz, C. (2011). The impact of Accounting Information Systems (AIS) on performance measures: empirical evidence in Spanish SMEs. The International Journal of Digital Accounting Research, 11, 25-43.

21. Wang, C., Wang, D., Abbas, J., Duan, K., \& Mubeen, R. (2021). Global financial crisis, smart lockdown strategies, and the COVID-19 spillover impacts: A global perspective implications from Southeast Asia. Frontiers in Psychiatry, 12.

22. Zutshi, A., Mendi J., \& Sarker, T. (2021). From Challenges to Creativity: Enhancing SMEs' Resilience in the Context of COVID-19. Sustainability, 13(12), Article 6542. 